\title{
Conservative Treatment of Pancreatic Trauma-An Experience from a Brazilian Trauma Center
}

\author{
1Domingos AF Drumond, ${ }^{2}$ Fabio M Botelho-Filho, ${ }^{3}$ Sizenando V Starling, ${ }^{4}$ Nathalia NG Lopes
}

\begin{abstract}
Introduction: This study wants to demonstrate that it is safe to treat pancreatic trauma conservatively in a developing country where resources are challenging.
\end{abstract}

Materials and Methods: The study analyzed data from a Brazilian trauma center.

Results: Thirteen patients from 2006 to 2017 had pancreatic trauma from low (I and II) and high grade (III) lesions and were treated conservatively. There was no mortality. Four patients had complications, but only one required laparotomy. In the study, a relationship was found with the degree of injury and time of hospitalization ( $p<0.011$ ), in addition to the presence of complications with the degree of complication $(p<0.021)$.

Conclusion: Conservative treatment of pancreatic trauma has been performed in low and high grade lesions. It is believed that as long as there is a 24-hour surgical team, such as computed tomography (CT), the treatment of pancreatic trauma can be well-conducted.

Clinical Significance: The study can decrease the number of unnecessary laparotomies.

Objetivo: Este estudo quer demonstrar que é seguro tratar o trauma pancreático de forma conservadora em um país em desenvolvimento onde os recursos são desafiadores.

Materiais e Métodos: $O$ estudo analisou dados de um centro de trauma brasileiro.

Resultados: Treze pacientes de 2006 a 2017 apresentaram trauma pancreático de baixo (I e II) e de alto grau (III), sendo tratados de forma conservadora. Não houve mortalidade. Quatro pacientes apresentaram complicações, mas apenas em um caso foi necessária laparotomia. No estudo, encontrou-se um relacionamento com o grau de lesão e tempo de internação ( p 0,011), além da presença de complicações com o grau de complicação (p 0,021).

Conclusão: o tratamento conservador do trauma pancreático é factível em lesões de baixo e alto grau. Acredita-se que, se houver uma equipe cirúrgica de 24 horas, com TC, o tratamento

\footnotetext{
${ }^{1}$ Chief Surgeon, ${ }^{2}$ Surgeon, ${ }^{3}$ Trauma Surgeon, ${ }^{4}$ General Surgeon

${ }^{1,3,4}$ General and Trauma Surgery, Hospital João XXIII, Belo Horizonte, Minas Gerais, Brazil

${ }^{2}$ Cirurgia, Hospital João XXIII, Belo Horizonte, Minas Gerais, Brazil

Corresponding Author: Fabio Mendes Botelho-Filho, Surgeon, Cirurgia, Hospital João XXIII, Belo Horizonte, Minas Gerais, Brazil, Tel: +553132230810, Email: mendesbotelho@hotmail. com
}

do trauma pancreático pode ser bem conduzido. Significância clínica: o estudo pode a diminuir o número de laparotomias desnecessárias.

Keywords: Abdominal trauma, Blunt trauma, Pancreas, Trauma.

How to cite this article: Drumond DAF, Botelho-Filho FM, Starling SV, Lopes NNG. Conservative Treatment of Pancreatic Trauma-an Experience from a Brazilian Trauma Center. Panam J Trauma Crit Care Emerg Surg 2018;7(2):97-101.

Source of support: Nil

Conflict of interest: None

\section{INTRODUCTION}

Trauma continues to be the main cause of mortality in Brazil among children and young adults (Datasus). ${ }^{1}$ The conservative treatment of solid organ lesions is a reality in trauma reference centers and it is today these organs' primary form of treatment. With the advent of new studies, especially in children, we know that the conservative treatment of pancreatic trauma is also becoming a reality.

Though less common than liver and/or spleen traumas (corresponding to less than 10\% of the contusions), pancreatic trauma is associated with a greater morbidity-mortality rate, given the severity of pancreatic complications, such as pancreatitis, and due to the concomitant presence of lesions in adjacent organs (Arkovitz, 1997; Subramanian, 2007; Mattix, 2007; Addison, 2016; Naik-Mathuria, 2017). ${ }^{2-6}$ The mortality of patients with pancreatic lesions can reach 3 to $8 \%$ (Bosboom 2006; Haugaard, 2012). ${ }^{7,8}$

Pancreatic trauma management is quite diverse in medical literature, especially concerning a degree III, IV, or $\mathrm{V}$ lesion (lesions with pancreatic duct lesions) (Haugaard 2014). ${ }^{9}$ Some authors advise that Degree I and II lesions should be treated conservatively, whereas Degree III, IV, and V lesions should be treated with surgery (Subramaniam, 2007). ${ }^{4}$ Other authors, observing the pancreatic lesions in children, have suggested that these cases should be treated without surgery, regardless of the degree, so long as the patient is stable (Shilyansky, 1998; Wales, 2001). ${ }^{10,11}$

In this scenario, this study presents a series of descriptive cases, demonstrating the success of conservative treatment, even for Degree III lesions in both children and adults in a Brazilian trauma reference center. 


\section{MATERIALS AND METHODS}

This study was conducted by analyzing the data from patients who underwent non-surgical treatment at the trauma reference hospital, Hospital João XXIII, in the city of Belo Horizonte, Brazil.

The line of research in this hospital focuses, in a prospective manner, on the data collection of all patients who have undergone the nonsurgical treatment of solid organs. It is important to note that all patients who had pancreatic injury (Grade I, II or III) without evidence of hollow visceral injury, diaphragmatic lesions or other formal indication of surgery were submitted to the conservative treatment. Then, during this time, there isn't a group of patients who underwent operative management just because of pancreatic injury in order to compare prognostic.

The collected variables included: age, year of trauma, trauma mechanism, the use of a CT for diagnoses, the presence of associated lesions, complications, the treatment of complications, time of hospitalization, and mortality.

From these data, patients with pancreatic trauma who had undergone conservative treatment between 2006 and September 2017 were selected.

This study also evaluated the association of the occurrence or not of complications with the degree of the lesions and the time elapsed before hospital discharge. Other associations were hindered by the small number of cases in the studied sample.

The comparison between the occurrence of complications and the degree of the lesion was carried out using Fisher's exact test.

The comparison between the occurrence and the time until hospital discharge was carried out by means of a Mann-Whitney test, given that the sample is small and that the assumption of normality (evaluated by the Shapiro-Wilk test) had been violated.

The analyzes were performed in the MINITAB program, version 18. A significance level of $5 \%$ was adopted.

The authors assert that all procedures contributing to this work comply with the ethical standards of the relevant national and institutional committees on human experimentation and with the Helsinki declaration of 1975, as revised in 2008.

\section{RESULTS}

The conservative treatment of pancreatic trauma corresponds to $0.4 \%$ of the cases treated without surgery, according to the analysis conducted between 2004 and 2016 in this hospital (Table 1).
Table 1: Number of cases treated in a conservative management stratified by solid organs. Failure rate between years 2004-2016

\begin{tabular}{lll}
\hline Organ & Total & Failure rate \\
\hline Liver & 1118 & $43(3,8 \%)$ \\
Spleen & 1038 & $82(7,9 \%)$ \\
Kidney & 653 & $36(5,5 \%)$ \\
Pancreas & 12 & $1(9 \%)$ \\
\hline
\end{tabular}

During the period corresponding to 2006 to 2017 (until September), 13 patients presented pancreatic trauma and received conservative treatment (Table 2 ) of these, 5 were patients under 18 years of age.

The average age was 26 years, while in the pediatric groups the average was 7.6 years.

The average trauma time until arriving at the hospital was of 61 hours. In three patients, it was impossible to estimate the exact time of the trauma. It should be noted that this study was conducted in a reference hospital that receives patients from the entire state, with the reference area estimated in $587,000 \mathrm{~km}^{2}$

The main cause of trauma was due to violence, followed by car and motorcylcle accidents. Degree I to III lesions received conservative treatment, understanding that this hospital, at that time, had not tried to implement treatments of Degree IV and V lesions without a laparotomy, because of the high incidence of complications and the high association with injuries that require operative treatment.

Four of the 13 patients presented complications, which included-two cases of pancreatitis, one case of a pseudocyst, and one case of an intra-abdominal abscess.

Only one patient with pancreatitis needed to be submitted to an exploratory laparotomy due to complications in pancreatitis. This patient had multiple abdominal collections and surrounded by small bowel and it was decided that percutaneous drainage would be unsafe. One patient with a pseudocyst and another with an intra-abdominal abscess were treated with percutaneous drainage guided by ultrasound.

The average time spent in the hospital was 16 days.

None of the patients died. The patients receive outpatient follow-up for a minimum period of three months after the trauma, so long as no complications have arisen before this time.

This study analyzed the comparisons between the occurrence or not of complications and the degree of the lesion in 13 patients. It was observed that $4(100.0 \%)$ patients with complications presented Degree III lesions, while among the 9 without complications, 3 (33.3\%) presented Degree I, 4 (44.5\%) patients presented Degree II, and $2(22.2 \%)$ patients presented Degree III lesions. For 
Table 2: Patients with pancreas injury submitted to conservative treatment

\begin{tabular}{|c|c|c|c|c|c|c|c|c|c|c|c|}
\hline & Age & Year & $E T T(h)$ & Mechanism & $C T$ & Grade & $\begin{array}{l}\text { Associated } \\
\text { injury }\end{array}$ & $\begin{array}{l}\text { Compli- } \\
\text { cation }\end{array}$ & $\begin{array}{l}\text { Complication } \\
\text { treatment }\end{array}$ & $\begin{array}{l}\text { Discharge } \\
\text { (days) }\end{array}$ & Death \\
\hline 1. & 44 & 2006 & 15 & Car accident & Yes & 1 & No & No & $N / A$ & 3 & No \\
\hline 2. & 35 & 2009 & 24 & Violence & Yes & 2 & No & No & $\mathrm{N} / \mathrm{A}$ & 7 & No \\
\hline 3. & 25 & 2010 & 288 & Violence & Yes & 3 & No & $\begin{array}{l}\text { Pancre- } \\
\text { atitis }\end{array}$ & Conservative & 19 & No \\
\hline 4. & 9 & 2010 & 12 & Bicycle & Yes & 3 & No & No & $\mathrm{N} / \mathrm{A}$ & 18 & No \\
\hline 5. & 7 & 2011 & 72 & Bicycle & Yes & 3 & No & $\begin{array}{l}\text { Pseudo- } \\
\text { cyst }\end{array}$ & Drainage & 40 & No \\
\hline 6. & 15 & 2012 & 5 & Car accident & Yes & 1 & No & No & $N / A$ & 5 & No \\
\hline 7. & 32 & 2012 & 72 & Violence & Yes & 3 & No & $\begin{array}{l}\text { Pancre- } \\
\text { atitis }\end{array}$ & Laparotomy & 33 & No \\
\hline 8. & 24 & 2012 & No data & Motorcycle & Yes & 2 & Yes & No & $\mathrm{N} / \mathrm{A}$ & 7 & No \\
\hline 9. & 39 & 2012 & No data & Fall & Yes & 2 & Yes & No & $N / A$ & 9 & No \\
\hline 10. & 5 & 2012 & 12 & Car accident & Yes & 3 & Yes & Colection & Drainage & 42 & No \\
\hline 11. & 75 & 2013 & No data & Motorcycle & Yes & 1 & Yes & No & $N / A$ & 5 & No \\
\hline 12. & 28 & 2016 & 40 & Motorcycle & Yes & 2 & Yes & No & $\mathrm{N} / \mathrm{A}$ & 7 & No \\
\hline 13. & 2 & 2017 & 72 & Violence & Yes & 3 & Yes & No & $\mathrm{N} / \mathrm{A}$ & 20 & No \\
\hline
\end{tabular}

ETT: Estimated time of trauma, CT: Computed tomography

this reason, the association of the low degree lesions (I, II) and high degree lesions (III) was analyzed. The p-value of 0.021 (p-value of less than 0.05 ) indicates a statistical significance in the comparison, that is, an association among the characteristics. The patients with high degree lesions (Degree III), therefore, have greater chances of presenting complications than do those with degree I or II lesions.

A statistical significance was also observed when comparing the presence of complications with the time until hospital discharge. It was found that four patients with complications presented a time until hospital discharge of, on average, $33.5 \pm 10.4$ and a median of 36.5 days. By contrast, the nine patients without complications presented a time until hospital discharge of, on average, $9.0 \pm 5.9$ and a median of 7.0 days. The $p$-value of 0.011 indicates that there is a statistically significant association between the time until hospital discharge and the complications. The patients with complications presented an estimate of the median for the time until hospital discharge of 26 days or more than those that did not suffer complications (CI 95\%: 12.0 to 35.0).

As only one patient required a laparotomy for the treatment of complications associated with pancreatitis, a success rate of $92 \%$ was considered to be the standard for conservative treatment of pancreatic lesions, regardless of the Degree of the lesion (I, II, or III).

\section{DISCUSSION}

The conservative treatment of pancreatic trauma is safe when the patients are separated out individually. One American multicenter study, conducted in 2007 (Mattix,
$2007)^{3}$, reported treatment success in $74 \%$ of the pediatric patients. This work favored early surgery in cases that identified a rupture of the pancreatic duct in diagnostic images.

Beres et al. (2013) published a report that compared children who received a conservative treatment of highdegree pancreatic lesions (III and IV) versus those who received surgical treatment. ${ }^{12}$ These authors found a higher time until hospital discharge, a higher time of parenteral use of 13 days or more and the presence of pseudocysts in the first group. Although only two laparotomies were necessary in the conservative treatment group, the authors tended to prefer early surgery, due to the significance of parenteral time and complications. Iqbal et al. (2015) reinforced the hypothesis that, in high-degree lesions, morbidity and time until hospital discharge would be greater with nonsurgical treatment. ${ }^{13}$ By contrast, Mora (2016) highlighted that patients who do not undergo an operation require a shorter treatment time in intensive care units than do patients who undergo an operation. ${ }^{14}$

In this Brazilian hospital, a statistical significance was also found in relation to the time of hospitalization ( $p<0.011)$ and to the degree of the lesion $(\mathrm{p}<0.021)$, and only one patient required a laparotomy to treat abdominal abscesses caused by pancreatitis.

The initial method of the image of choice to evaluate the abdominal lesion that is suspected to be a pancreatic lesion is through a $\mathrm{CT}$ of the abdomen with intravenous contrast. When the $\mathrm{CT}$ image raises a doubt, an endoscopic retrograde cholangiopancreatography 
(ERCP) can diagnosis up to $100 \%$ of the duct lesions (Bhasin, 2009). ${ }^{15}$ However, such a modality is restricted to some specific trauma centers. Magnetic resonance cholangiopancreatography (MRCP) is also an alternative method, which is more accurate than the CT exam, but depends on the sedation of pediatric patients. Again, this procedure is not available in all hospitals (Nirula, 1999). ${ }^{16}$ CT images that corroborate with the pancreatic duct lesion are deep lacerations and pancreatic transection (Fig. 1) ${ }^{17}$ It should be noted that the $\mathrm{CT}$ accuracy increases depending on the moment in which the CT was performed. Therefore, more recent CTs may not fully reveal the pancreatic lesion. In these cases, it is advisable to repeat the CT 12 hours later, when the CT accuracy is more reliable (Rekhi, 2010; Sheikh, 2015). ${ }^{17,18}$ In the hospital where this study was conducted, the CT is used as an initial method of choice for all cases. The ERCP is not entirely available at the João XXIII Hospital, but, if necessary, it can be performed in partner hospitals.

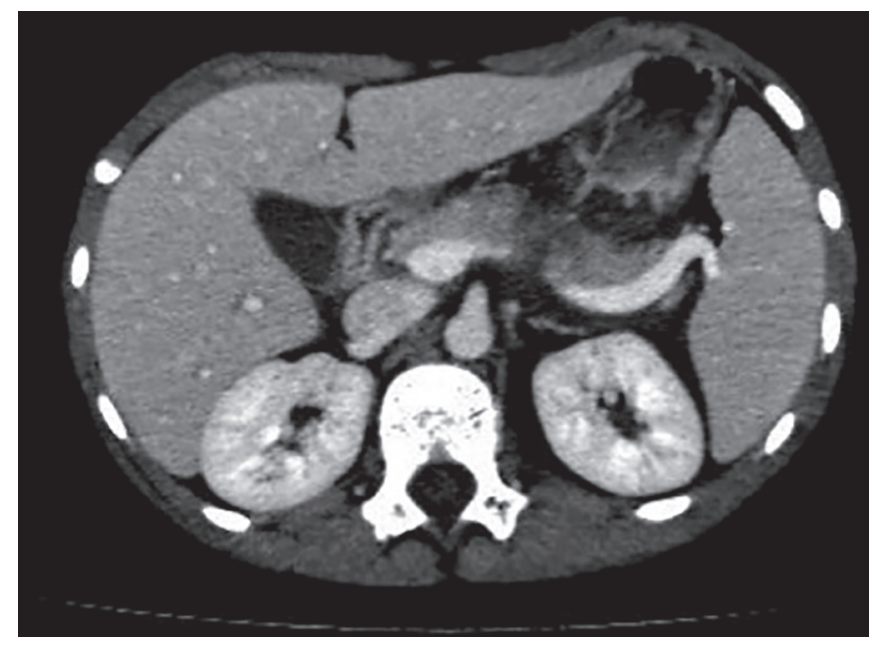

Fig. 1: CT demonstrating pancreatic duct injury

The importance of diagnosing the pancreatic duct lesion or not is because it is common knowledge that patients with this type of lesion are more prone to complications, especially pseudocysts.

In trauma, the incidence of pseudocysts can reach $44 \%$ and are related to pancreatic duct trauma (De Blaauw, 2008). ${ }^{19}$ Its treatment can be conservative, through external or internal drainage, or surgical. Russel (2013) demonstrated the success of conservative treatment (observation and/or only drainage) in up to $76 \%$ of the pseudocysts in children's pancreatic trauma. ${ }^{20}$ Treatment success through drainage also occurred in a 7-year-old patient in this study (Fig. 2).

The present study shows that pancreatic trauma treatment is a reality in a developing country. In Degree I and II lesions, the success of conservative treatment
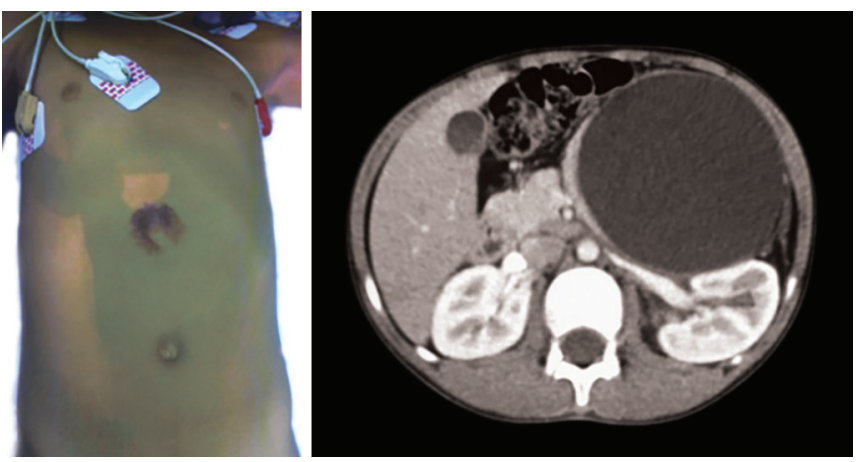

Fig. 2: Pancreatic trauma complicated by pseudocyst

has been well documented and was corroborated by the data presented in this study with a 100\% success rate. In high degree lesions, this study also demonstrated that it is possible to treat patients with Degree III lesions with conservative treatment. Even if the number of complications is higher, these can be treated with minimally invasive techniques, diminishing the morbidity-mortality rate of a laparotomy. If we consider the absence of laparotomy as a definition of the success of conservative treatment, we can conclude that the success of conservative treatment reached a $92 \%$ success rate in this work.

It is also important to remember that, with the accumulation of experience and with the incentive of new publications, these patients' time of hospitalization tends to diminish.

It is also recommended that the treatment of these patients be made in a reference center in which are available: surgical team, 24-hour CT exams and access to MRCP and ERCP.

\section{CONCLUSION}

The conservative treatment of pancreatic trauma is now being more widely studied in medical literature. Due to the rarity of this trauma, prospective studies with an expressive number of cases in a trauma center are difficult to obtain, especially in developing countries.

The present work shows that is possible and safe to treat pancreatic injuries (Grade I, II and III) without laparotomy in a developing country.

\section{CLINICAL SIGNIFICANCE}

The conservative treatment of pancreatic lesions is possible for Grade I, II and III injuries, decreasing laparotomies rate.

\section{ACKNOWLEDGMENT}

Authors would like to thank Richard Falcone Jr. and Cincinnati Children's Trauma Service for the continued encouragement of our work. 


\section{REFERENCES}

1. Brazilian Health Information. Datasus. Available in: $<\mathrm{http}: / /$ www2.datasus.gov.br/DATASUS/index.php?area=0205>. Access in June 30th, 2017.

2. Arkovitz MS, Johnson N, Garcia VF. Pancreatic trauma in children: mechanisms of injury. J Trauma 1997;42:49-53.

3. Mattix KD, Tataria M, Holmes J, Kristoffersen K, Brown R, et al. Pediatric pancreatic trauma: predictors of nonoperative management failure and associated outcomes. J Ped Surg 2007; 42:340-344.

4. Subramanian A, Dente CJ, Feliciano DV. The management of pancreatic trauma in the modern era. Surg Clin North Am 2007;87: 1515-1532.

5. Addison P, Iurcotta T, Amodu LI, et al. Outcomes following operative vs. non-operative management of blunt traumatic pancreatic injuries: a retrospective multi-institutional study. Burns \& Trauma. 2016;4:39. doi:10.1186/s41038-0160065-5.

6. Naik-Mathuria BJ, Rosenfeld EH, Vogel A, Gosain A, Burd R, Falcone RA Jr, et al. And the Pancreatic Trauma Study Group (PTSG) Collaborators. Proposed Clinical Pathway for NonOperative Management of High-Grade Pediatric Pancreatic Injuries based on a Multicenter Analysis: A Pediatric Trauma Society Collaborative. J Trauma Acute Care Surg. 2017.

7. Bosboom D, Braam AW, Blickman JG, Wijnen RM. The role of imaging studies in pancreatic injury due to blunt abdominal trauma in children. European Journal of Radiology 2006;59(1):3-7.

8. Haugaard MV, Penninga L, Ifaoui IB, Qvist N, Wettergren A. Pancreatic trauma in children - operative versus nonoperative treatment. Ugeskrift for Laeger (Journal of the Danish Medical Association) 2012;174(3):115-119.

9. Haugaard MV, Wettergren A, Hillingsø JG, Gluud C, Penninga L. Non-operative versus operative treatment for blunt pancreatic trauma in children. Cochrane Database of Systematic Reviews 2014, Issue 2. Art. No.: CD009746. DOI:10.1002/14651858.CD009746.pub2.
10. Shilyansky J, Sena LM, Kreller M, Chait P, Babyn PS, Filler RM, et al. Nonoperative management of pancreatic injuries in children. Journal of Pediatric Surgery 1998;33(2):343-349.

11. Wales PW, Shuckett B, Kim PC. Long-term outcome after nonoperative management of complete traumatic pancreatic transection in children. Journal of Pediatric Surgery 2001;36 (5):823-827.

12. Beres $\mathrm{AL}$, Wales PW, Christison-Lagay ER, McClure ME, Fallat ME, Brindle ME. Non-operative management of highgrade pancreatic trauma: is it worth the wait? J Pediatr Surg 2013; 48(5):1060-1064.

13. Iqbal CW, St Peter SD, Tsao K, et al. Operative vs nonoperative management for blunt pancreatic transection in children: multi-institutional outcomes. J Am Coll Surg 2014;218:157-62.

14. Mora MC, Wong KE, Friderici J, Bittner K, Moriarty KP, et al. Operative vs Nonoperative Management of Pediatric Blunt Pancreatic Trauma Data Bank. J Am Coll Surg 2016;222(6): 977:982.

15. Bhasin DK, Rana SS, Rawal P. Endoscopic retrograde pancreatography in pancreatic trauma: need to break themental barrier. J Gastroenterol Hepatol 2009;24:720.

16. Nirula R, Velmahos GC, Demetriades D. Magnetic resonance cholangiopancreatography in pancreatic trauma: a new diagnostic modality? J Trauma 1999;47:585.

17. Sheikh F, Fallon S, Bisset G, Podberesky D, Zheng J, et al. Image-guided prediction of pseudocyst formation in pediatric pancreatic trauma. Journal of Surgical Research 2015. 193:513-518.

18. Rekhi S, Anderson SW, Rhea JT, Soto JA. Imaging of blunt pancreatic trauma. Emerg Radiol 2010;17:13.

19 de Blaauw I, Winkelhorst JT, Rieu PN, van der Staak FH, Wijnen MH, Severijnen RS, van Vugt AB, Wijnen RM (2008) Pancreatic injury in children: good outcome of nonoperative treatment. J Pediatr Surg 43(9):1640-1643.

20. Russel KW, Barnhart DC, Madden J, Leeflang E, Jackson WD, et al. Non-operative treatmen versus percutaneous drainage of pancreatic psuedocysts in children. Pediatr Surg Int 2013. 29:305-310. 